\title{
Erratum to: The descriptive content of names as predicate modifiers
}

\section{Olga Poller ${ }^{1}$}

\section{Erratum to: Philos Stud DOI 10.1007/s11098-016-0801-5}

In the original publication of the article, the last sentence in the Acknowledgements section was incorrectly published as "This project was supported by the Ministry of Science and Higher Education of Poland, DEC-2012/05/N/HS1/01429". The correct sentence should read as "This project was supported by the National Science Centre of Poland, DEC-2012/05/N/HS1/01429”.

The online version of the original article can be found under doi:10.1007/s11098-016-0801-5.

\section{Olga Poller}

kukuxa@gmail.com

1 Institute of Philosophy, Jagiellonian University, Grodzka St. 52, 31-044 Cracow, Poland 